\title{
DATING THE BRONZE AGE OF SOUTHEAST ASIA. WHY DOES IT MATTER?
}

\author{
Charles Higham \\ Department of Anthropology, University of Otago, P.O. Box 56, Dunedin, New Zealand \\ Email: charles.higham@otago.ac.nz \\ Thomas Higham

\begin{abstract}
Oxford Radiocarbon Accelerator Unit, Research Lab for Archaeology and the History of Art, University of Oxford, 1 South Parks Road, Oxford OX1 3TG, United Kingdom

Email: thomas.higham@arch.ox.ac.uk
\end{abstract}

Katerina Douka

Max Planck Institute for the Science of Human History, Kahlaische Str. 10, 07745 Jena, Germany

Email:douka@shh.mpg.de

Keywords: Ban Chiang, Ban Non Wat, Bronze Age, chronology, knowledge transmission, social change

\begin{abstract}
We have dated human bone, freshwater shell, charcoal and rice grains from key sites in mainland Southeast Asia in order to establish the chronological scaffolding for later prehistory (ca $2500 B C-A D$ 500). In a recent report on the metal remains from the site of Ban Chiang, however, this chronology has been challenged. Here, we respond to these claims and show that they are unfounded and misleading. We maintain the integrity of the Bayesian-modelled radiocarbon results that identify the arrival of the first rice and millet farmers in mainland Southeast Asia towards the end of the 3rd millennium $B C$, with the first evidence for the mining, smelting and casting of bronze by about $1100 \mathrm{BC}$. Social change that followed the establishment of metallurgy was rapid and profound.
\end{abstract}

\section{INTRODUCTION}

Any investigation into the origins, spread of technical knowledge and the social impact of copper-base metallurgy in mainland Southeast Asia must begin with a robust chronology. We have obtained multiple radiocarbon dates from secure contexts, and by employing the latest pre-treatment protocols and Bayesian analysis of the results, identified the temporal span of cultural phases, that leads to as precise a chronology as possible. In this, we follow Bayliss et al. (2007:24) when they wrote:

Timetables of the sort presented in these papers are now not only achievable on a routine basis, but are a necessity if we are to address fundamental questions about our pasts, including the experience of the flow of life, the social marking of time.

By obtaining over 200 new radiocarbon determinations from key sites in Northeast and Central Thailand, north-central Myanmar, Vietnam, Laos and southern provinces of China, we suggest that the chronological scaffolding is now in place, and regional specialists can move with assurance to exploring how the technical knowledge of copper and tin alloying reached Southeast Asia, how was it deployed, and what was its social impact (Higham and Higham 2009; Higham et al. 2015; Castillo et al. 2018; Pryce et al. 2018). We find that rice and millet farmers expanded south from the Yangtze and Yellow River regions by different routes, reaching Baiyangcun in Yunnan by ca. $2650 \mathrm{BC}$ (Figure 1; Dal Martello et al. 2018), coastal Vietnam and Thailand by 2200-2000 BC, and the interior Khorat Plateau by 1700-1500 BC (Higham et al. 2015). 


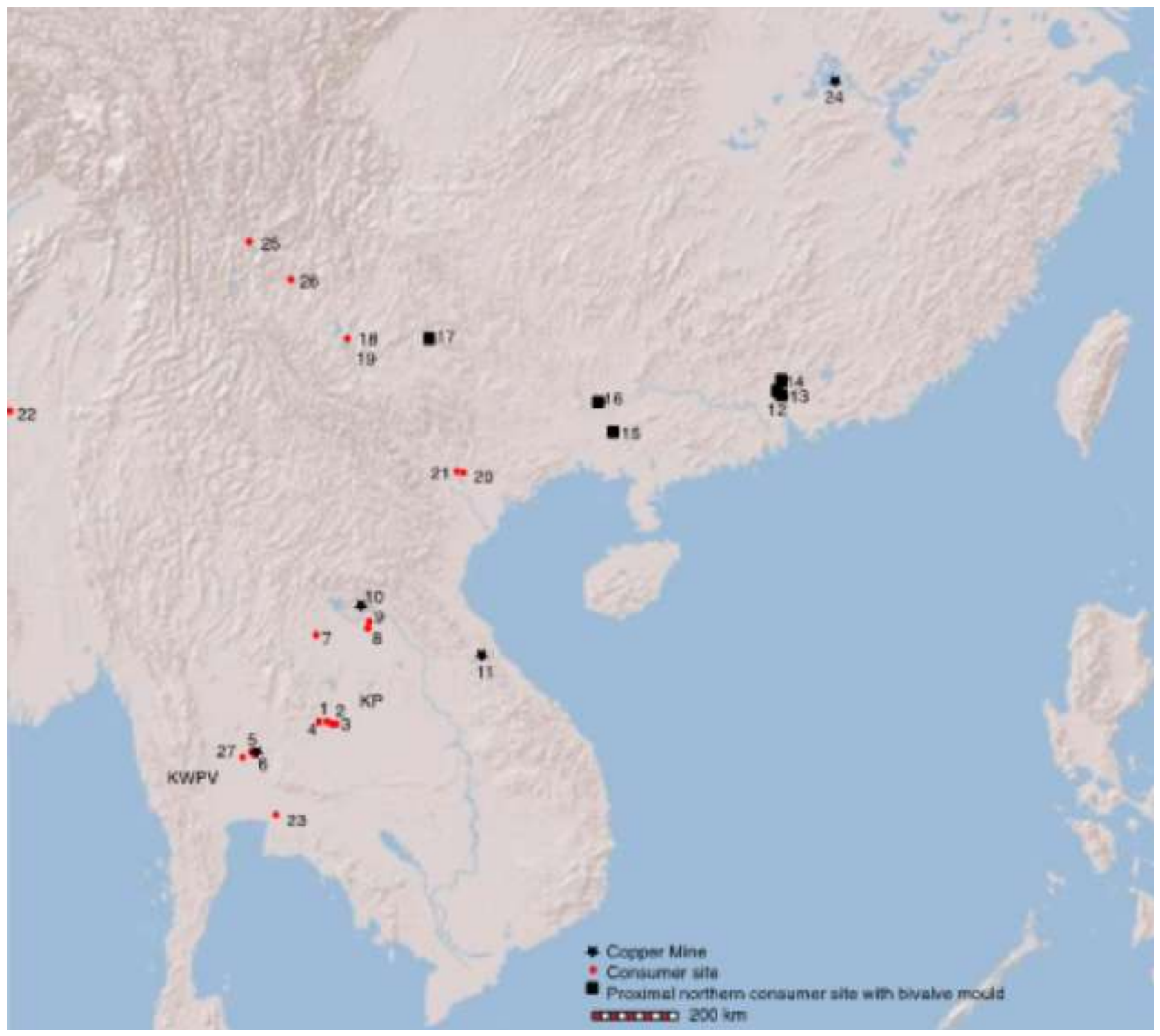

Figure 1. The location of sites mentioned in the text. 1. Ban Non Wat, Noen U-Loke, 2. Ban Lum Khao, 3. Ban Prasat, 4. Non Ban Jak, 5. Non Pa Wai, 6. Nil Kham Haeng, 7. Non Nok Tha, 8. Ban Na Di, 9. Ban Chiang, 10. Phu Lon, 11. The Vilabouly complex, 12. Tangxiahuan, Dameisha, Guoluwan, 13. Yapowan, Nanshawan, Zengchuanbu, 14. Longxue, 15. Gantuoyang, 16. Yuanlongpo, 17. Wayao, 18. Hebosuo, 19. Shangxihe, 20. Dong Dao, Go Mun, 21. Than Den, 22. Oakaei, 23. Khok Phanom Di, 24. Tonglüshan, 25. Haimenkou, 26. Baiyangcun, 27. Ban Mai Chaimongkol. Illustration by Charles Higham. 
Geochemical analyses of the sediments in Lake Erhai in Yunnan suggest that the first copper smelting in the area took place from the mid $2^{\text {nd }}$ millennium BC (Hillman et al. 2015), while the first copper-base artefacts in this province have been dated at Hebosuo and Shangxihe from ca. 1100 BC (Yao and Darre 2019 in press). We have dated the earliest metal items in Southeast Asian sites similarly, to the late second millennium BC. These were probably imports from established workshops in Lingnan to the north, followed almost at once by the discovery of copper sources and establishment of production centers quite probably by immigrant practitioners (Pryce 2009; Pryce et al. 2010, 2011). Copper-base axes and ornaments at the key site of Ban Non Wat joined exotic marine shell and marble as mortuary offerings in the graves of aggrandizer social elites within a century, in a cemetery covering several generations between ca. 1050-850 BC (Higham and Kijngam 2012).

This new chronological framework has been challenged by White (2018). In reporting on the metal remains from the site of Ban Chiang, White has set out in detail the grounds for her longer chronology model, that dates the first copper-base industry there between 2000-1800 BC. Resolving this difference is important to regional specialists because by extending the duration of the Bronze Age by nearly a millennium, it is necessary to seek different points of origin, different means for the transfer of technical knowledge, and set any social and technological changes within a much longer time span.

\section{BAN NON WAT}

The cultural sequence at Ban Non Wat is of long duration. A deep basal shell midden in the same layer as an infant skeleton has been dated to 22,247-20,891 cal. BC. After a long hiatus, further probable hunter-gatherer burials date from about $1750 \mathrm{BC}$, followed by two Neolithic, six Bronze Age and three Iron Age mortuary and occupation phases (Higham and Kijngam 2009) that contained c. 700 burials. The chronology for the main excavated area has been determined by 75 radiocarbon determinations on the basis of freshwater bivalve shells $(n=50)$, charcoal $(n=21)$ and the organic temper from pottery vessels $(n=4)$ (Figure 2 ). The four experimental ceramic temper determinations have been fully reported (Higham et al. 2010). The resultant Bayesian sequence covers 2300 years (Figure 2), from $1750 \mathrm{BC}$ to $\mathrm{AD} 500$. White has claimed that insufficient pretreatment protocols were applied to the shell samples to rule out possible diagenesis and that the determinations might be inaccurately late (White 2015). We have responded to this in detail (Higham et al. 2015), but this was disregarded (White 2018:34). Let us, for the moment at least, set the shell dates aside, and turn to the charcoal dates from Ban Non Wat (Figure 3). These show that initial Neolithic occupation dates from c. $1650 \mathrm{BC}$, and the transition into the initial Bronze Age took place in circa the 11th century BC. White has proposed that the shell dates are inaccurately late while the charcoal dates might be too early due to inbuilt age. They both present an identical sequence.

We therefore, provide a further detailed examination of the grounds for our 11th century $\mathrm{BC}$ date for early bronze. In square $\mathrm{Y}$ at Ban Non Wat, we uncovered burials in which the pottery vessels placed as mortuary offerings are beyond doubt, of the second phase of the Bronze Age sequence. This followed immediately from the short-lived Bronze Age 1. These graves were cut down to and on occasion through four hearths containing charcoal (Figure 4). The calibrated radiocarbon determinations for these are: 1124-921 BC, 1121-894 BC, 1111-929 BC and 1056-905 BC, again supporting the overall chronology.

White (2018:33) does support dating rice grains. In her own words: "Unfortunately, dates from the most desirable samples, such as charred short-lived plant foods like cereal grains excavated from impeccable contexts ... are very rare in Southeast Asia." We have obtained 14 new AMS radiocarbon dates on charred rice grains from square N96 at Ban Non Wat. The new dates confirm those from both charcoal and shell (Figure 5; Castillo et al. 2018). We have thus furnished radiocarbon determinations from shell, charcoal and rice grains, all from impeccable contexts, each 


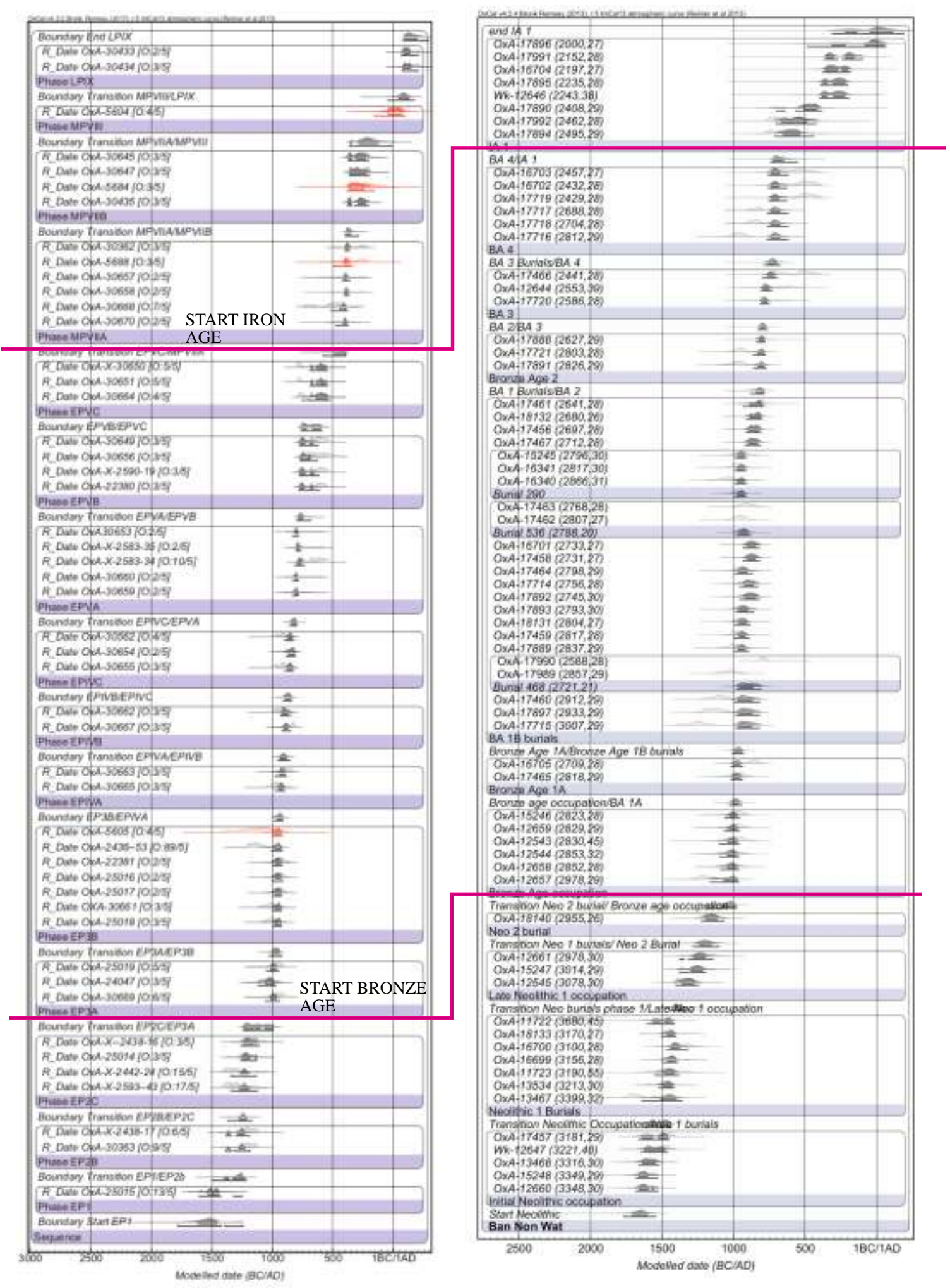

Figure 2. The Bayesian plot for Ban Chiang (left) and Ban Non Wat. Dates in red for Ban Chiang are derived from organic temper extracted from mortuary vessels, devoid of clay, that were rejected by Glusker and White (1997) as being erroneously late. Illustrations by Charles Higham. 


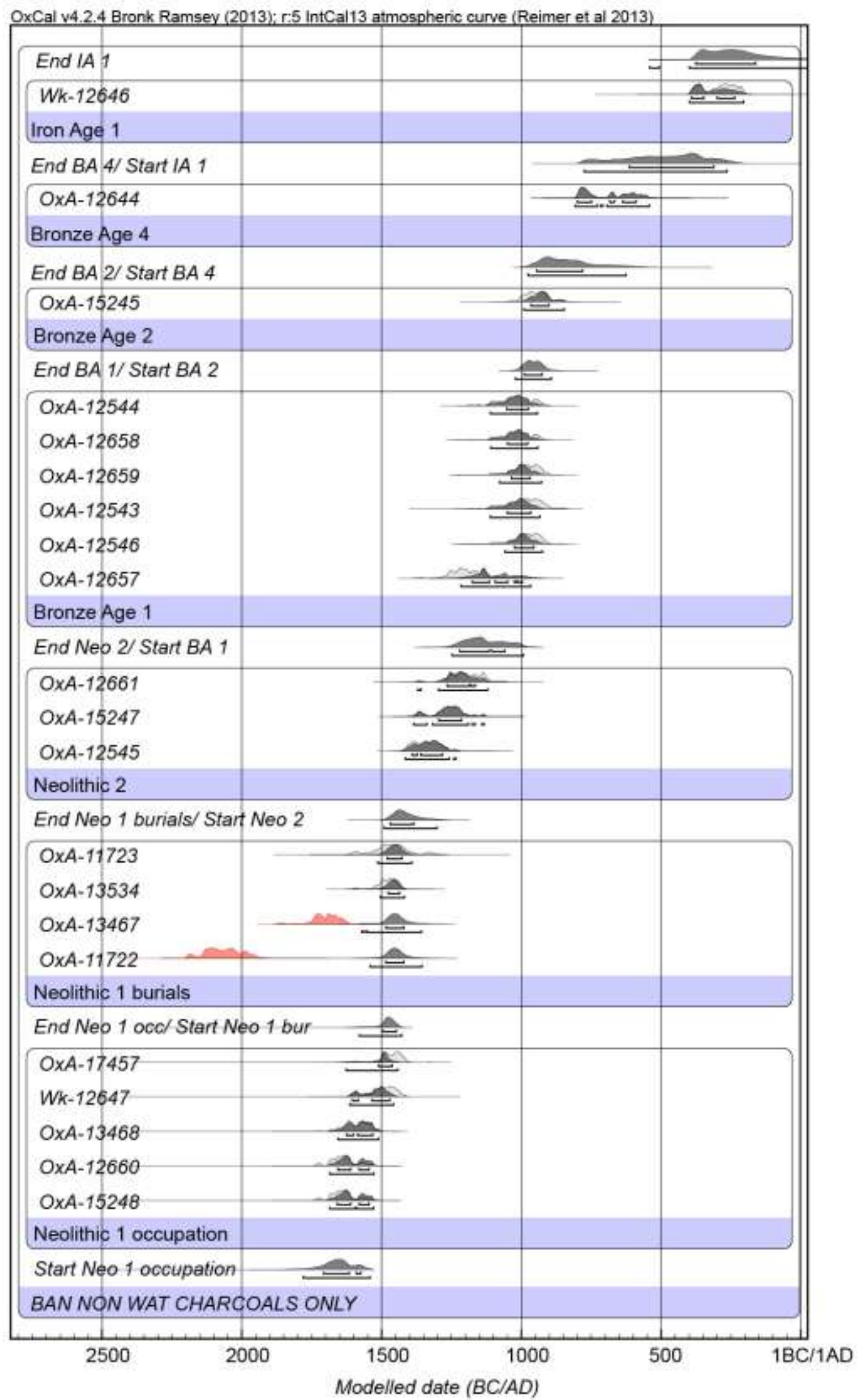

Figure 3. Bayesian plot of the radiocarbon determinations from Ban Non Wat derived only from charcoal. Illustration by Charles Higham. 


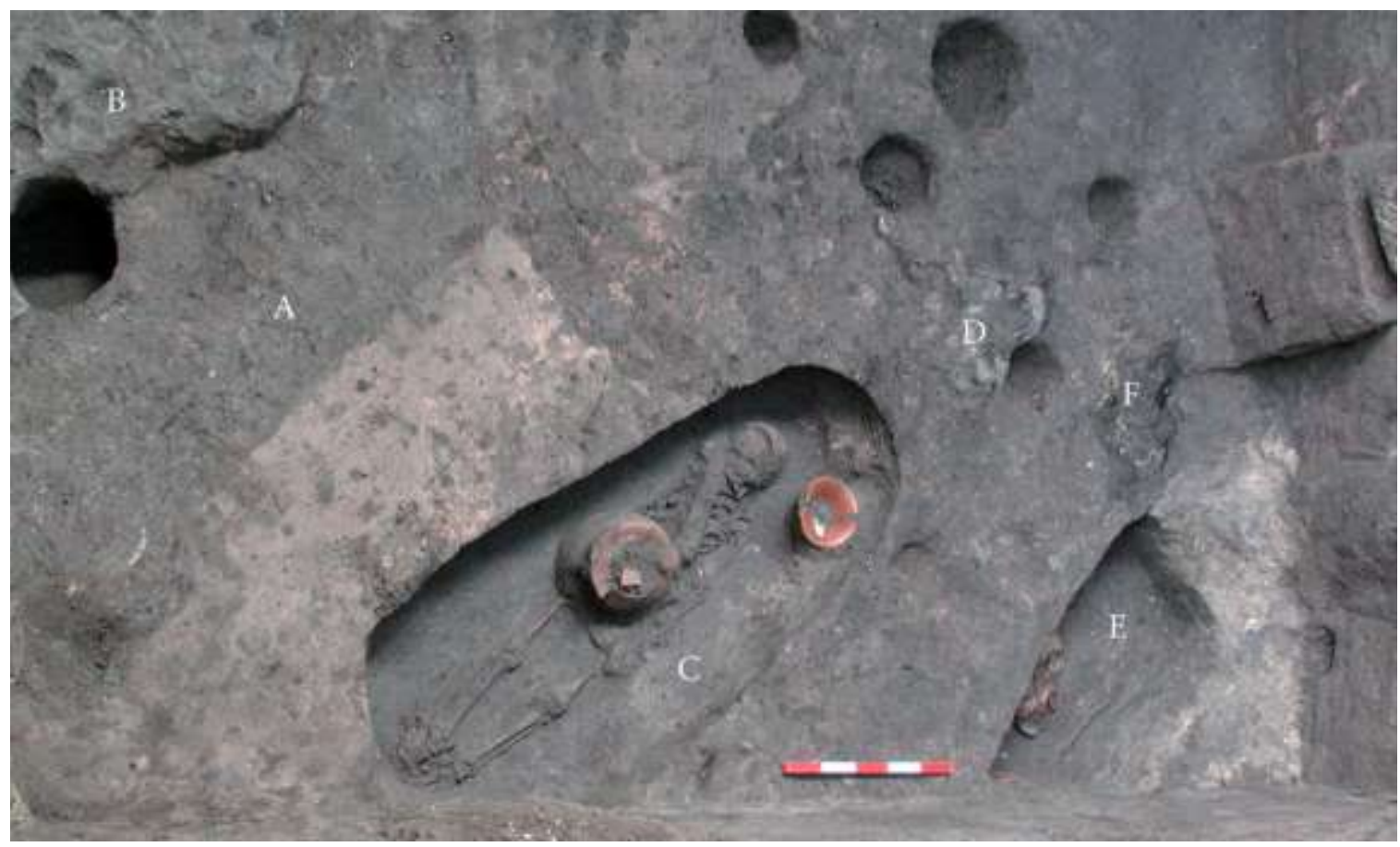

Figure 4. Ban Non Wat, the surface of layer 8:4 in square Y, showing the relationship between the early Bronze Age burials and hearths that have provided radiocarbon determinations. A. The grave cut for burial 97. B. Hearth 8:4 feature 1 (1127-850 cal. BC). C. Burial 94. D. Hearth 8:4 feature 2(1127-927 cal. BC). E. Burial 96. F. Hearth 8:4 feature 3 (1108-905 cal. BC. Photograph by Charles Higham. 


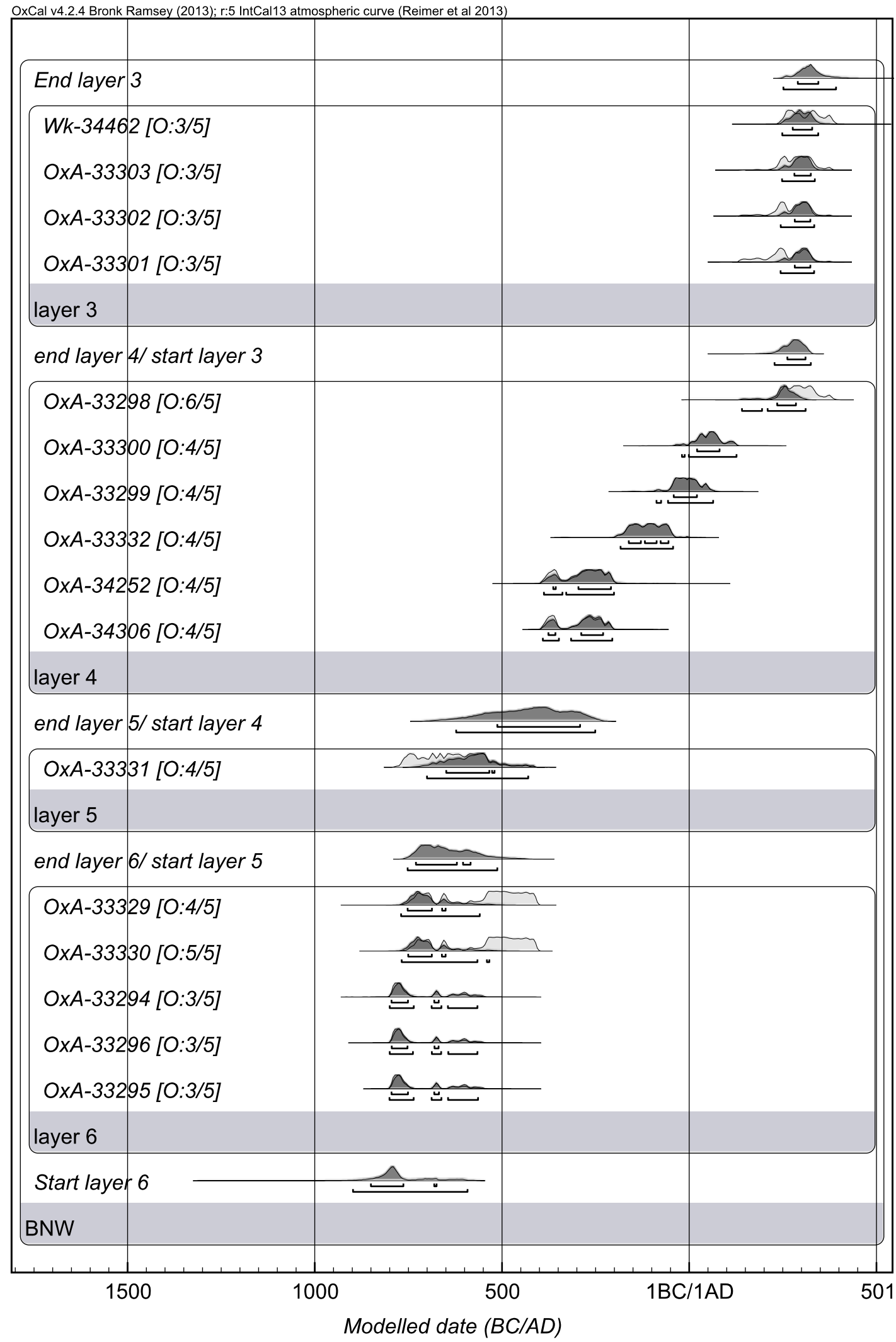

Figure 5. Bayesian model for Ban Non Wat square $N 96$ on the basis of rice grains. Illustration by Charles Higham. 
providing the same chronology. This provides strong support for the overall chronology for the initial Neolithic and Bronze Age sequence on the Khorat Plateau.

\section{BAN CHIANG}

Southeast Asian archaeologists ... know they must tolerate some degree of chronological fuzziness (White 2008:101).

The less formal approaches to interpreting radiocarbon dates which are very widely used by prehistorians are very frequently importantly wrong and misleading. Not only does it appear that human activities which may in fact have been separated by centuries were contemporary, but it also appears, erroneously, that activities lasted much longer than they did in reality (Bayliss et al. 2007:24).

The 1974-5 excavation of Ban Chiang was directed by Chester Gorman and Pisit Charoenwongsa. When Gorman died in 1981, the Museum of the University of Pennsylvania appointed Joyce White to direct the analyses and publish the findings. Having been involved in both seasons of fieldwork, one of us $(\mathrm{CH})$ has every reason to sympathize with this onerous responsibility. As Armit (2015:755) has stressed:

Writing up someone else's excavation is always difficult. Missing sections, duplicated context numbers and misinterpreted stratigraphic relationships are all par for the course....

White (1994) has confronted this truism, writing that:

One could certainly wish for much clearer and more accurate records of the excavation of the square but "human error" or at least "human variability" is in evidence throughout the records. Higham's xeroxed plans demonstrate an example of the maddening inconsistency of placement of features which continue from layer to layer in some instances. Sorting out degrees of reliability must take into consideration many factors includ- ing who was excavating and who was recording the notes and plans.

As excavations progressed, Gorman and C. Higham had numerous discussions on the site's stratigraphy. The degree of disturbance and bioturbation is unparalleled in any other site the latter has excavated, and this may have contributed to the long delay of the final publication. (White (1994) wrote that "publication of the first volume on chronology and stratigraphy is scheduled for January 1997", but this has not materialized yet.)

It would not be easy for the interested reader unfamiliar with this site, to untangle her version of the cultural sequence. White has subdivided the mortuary sequence into 21 phases (Table 1) with labels that have meaning for this site only. This makes it virtually impossible to discuss the site in a broader context. For example, how do you relate Early Period IVc, or Middle Period VIIb, with the cultural sequence at any other site? Here we have simplified this unnecessarily detailed sequence for each excavated area and identify two Neolithic, two Bronze Age and two Iron Age phases (Table 1).

Excavations took place in two different parts of the site. The 1974 season opened an area of $72.3 \mathrm{~m}^{2}$ in the back yard of a house that had not been looted. The sequence began with a single early Neolithic burial found at a depth of $2.78 \mathrm{~m}$ below datum (mbd) which we have directly dated on the basis of bone collagen to 15451475 BC. This was followed by a group of burials interred at depths between 1.66-2.32 mbd. Our new radiocarbon dates for these are remarkably consistent, varying between 14131257 BC and 1219-1049 BC. These are late Neolithic. There are just three burials that belong to the early Bronze Age at this site and there are no bone collagen dates for these. We then enter a period of the later Bronze Age. There are three bone collagen dates for the 27 burials, falling in the 9th and 8th centuries BC. Burial 23 is one of these, and was interred with a socketed bronze axe and four bangles. The early Iron Age is represented by two burials, one of which dates to 401-353 BC (65\% probability) or $292-231$ BC (30\% probability), the variability reflecting the Hallstatt Plateau in the 
Table 1. The cultural sequence from Ban Chiang 1974-5 excavation seasons. Burials in bold contained a bronze mortuary offering.

\begin{tabular}{|c|c|c|c|c|c|}
\hline \multicolumn{4}{|c|}{ Ban Chiang 1975} & \multicolumn{2}{|c|}{ Ban Chiang 1974} \\
\hline Period & $\begin{array}{l}\text { Mortuary } \\
\text { Phase }\end{array}$ & Burial & $\begin{array}{l}\text { Designation } \\
\text { (By C. Higham) }\end{array}$ & $\begin{array}{l}\text { Mortuary } \\
\text { Phase }\end{array}$ & Burial \\
\hline & LPX & 1237813 & \multirow{2}{*}{ LATE IRON AGE } & LPX & 13145155 \\
\hline & LPIX & 4569 & & LPIX & \\
\hline & MPVIII & 12 & \multirow{3}{*}{ EARLY IRON AGE } & MPVIII & \\
\hline & MPVIIb & $\begin{array}{l}11192022 \mathbf{2 3} \mathbf{2 4} \\
\mathbf{2 6} \mathbf{8 0}\end{array}$ & & MPVIIb & 22 \\
\hline & MPVIIa & $\begin{array}{l}10 \mathbf{1 4} 15 \mathbf{1 6} 17 \mathbf{4 0} \\
4171737578\end{array}$ & & MPVIIa & 11 \\
\hline & MPVI & 2125 & \multirow{4}{*}{ LATE BRONZE AGE } & MPVI & 4915171820 \\
\hline \multirow{3}{*}{$\begin{array}{l}\text { UPPER } \\
\text { EARLY } \\
\text { PERIOD }\end{array}$} & EPVc & 2829303253 & & EPVc & $\begin{array}{l}567810121316 \\
192849\end{array}$ \\
\hline & $\mathrm{EPVb}$ & 273656 & & $\mathrm{EPVb}$ & \\
\hline & EPVa & 334259 & & EPVa & $\begin{array}{l}212329303637 \\
3950\end{array}$ \\
\hline \multirow{12}{*}{$\begin{array}{l}\text { LOWER } \\
\text { EARLY } \\
\text { PERIOD }\end{array}$} & EPIVc & $\begin{array}{l}31343537 \mathbf{3 8} 48 \\
6482\end{array}$ & \multirow{8}{*}{ EARLY BRONZE AGE } & EPIVc & \\
\hline & EPIVb & 4661636677 & & EPIVb & \\
\hline & EPIVa & 435051545569 & & EPIVa & 26 \\
\hline & EPIII-IV & 4565 & & EPIII-IV & 3154 \\
\hline & EPIIIb & 44474970 & & EPIIIb & \\
\hline & EPII-IV? & 6768 & & EPII-IV? & \\
\hline & EPII-III & 58727981 & & EPII-III & \\
\hline & EPIIIA & 49A 526276 & & EPIIIA & \\
\hline & EPIIc & 576074 & \multirow[t]{3}{*}{ LATE NEOLITHIC } & EPIIc & $\begin{array}{l}244346333438 \\
404245\end{array}$ \\
\hline & EPIIb & & & EPIIb & 32414752 \\
\hline & EPIIa & & & EPIIa & 2548 \\
\hline & EPI & & EARLY NEOLITHIC & EPI & 44 \\
\hline
\end{tabular}


radiocarbon calibration curve that produces this bimodal distribution. There are five burials of the later Iron Age, none of which has been dated.

Excavations in 1975 took place in a narrow lane. Just $4 \mathrm{~m}$ wide, the area opened covered $58.5 \mathrm{~m}^{2}$. There is one late Neolithic burial in this square, which we have dated 1411-1257 BC. This was followed by an early Bronze Age cemetery in which the dead were laid out in three rows. The 15 radiocarbon determinations on bone collagen indicate that this was of brief duration, starting in about $1000 \mathrm{BC}$ and lasting for little over a century. The later Bronze Age is represented by 12 burials, covering the late 9 th to the end of the 7th century BC. The early Iron Age burials form two clusters. The bone collagen dates range from the early 5 th century to the 3rd century BC. Finally, there are 11 late Iron Age burials dated to the 1st and 2nd centuries AD.

The initial claims for the earliest bronze and iron technologies in the world (Gorman and Charoenwongsa 1976) have long since been set aside. In their place, White has turned to dating rice chaff temper from mortuary pots (White 1997, 2008; Glusker and White 1997; White and Hamilton 2009). This has involved a continuous thread in favour of as early a chronology as can be derived from the available data, while ignoring the later dates, the reasons for which are hard to identify. This runs contrary to universally accepted practice in interpreting a set of radiocarbon determinations, and it is necessary to examine how this has unfolded.

Eight determinations come from the Arizona radiocarbon laboratory, 12 from the Oxford radiocarbon laboratory and one, on rice phytoliths, from the Center for Accelerator Mass Spectrometry (Table 2, Figure 6). The Oxford sample is divided on the basis of pretreatment into crushed sherds on the one hand, the isolated organic fraction, and two samples (OxA-5685, -5689) where enough humic acid fraction was recovered to date it separately. The determinations from the isolated organic fraction when dating the same pot, are markedly younger than those from crushed potsherds, but Glusker and White's comments reflect their prejudice for the early options. Two samples from 1975 burial 12 are respectively $119 \mathrm{BC}-$ AD 142 AD for rice chaff and 1317-1047 BC for crushed potsherd. Glusker and White find the former "substantially too young". Other comments follow the same reasoning: "the husk/etc. date is younger than archaeological expectations" and "the husk/etc. date barely extends into the young end of the range of an archaeologically acceptable date" (Glusker and White 1997:259-260). Translated, this means that they do not support White's preferred long chronology, and are therefore manipulated into oblivion. By thus winnowing out the late dates, we are left with just seven out of 21 . It is essential to appreciate that these seven hand-picked determinations underwrite her chronology for this site: the earliest copper-base metallurgy there dates, she has widely claimed, between 2000-1800 BC (White and Hamilton 2009).

There was an initial enthusiasm for dating ceramic temper, as it seemed to resolve problems of inbuilt age and assured context. Many were initially supportive. However, specialists have subsequently identified multiple sources of possible contamination. As Berstan et al. (2008:702) have noted: "Direct radiocarbon dating of pottery is relatively uncommon due to the presence of carbon sources with differing ages, for example geological carbon remaining in the clay after firing, added organic temper, carbon from fuel in the kiln and exogenous contaminants absorbed from the burial environment." (see also Bonsall et al. 2002; Higham et al. 2015). Moreover, pretreatment methods and what you actually date will affect the results. Even the seven selected dates are internally inconsistent. That for Early Bronze Age burial 34 is earlier than the result for late Neolithic burial BC 46. The gap of 350 years between the dates for burial 59 of EPVa and burial 56 of EPVb is archaeologically untenable. The former is only $28 \mathrm{~cm}$ lower, and these two burials are placed lineally on the same orientation. At Ban Non Wat and Ban Lum Khao, this disposition is found invariably with virtually contemporary burials. Nevertheless, based on seven handpicked dates, White concludes that her evidence "may relate to a rapid and broad spread of 
Table 2. The AMS dates for Ban Chiang on the basis of ceramic temper.

\begin{tabular}{|c|c|c|c|c|c|c|}
\hline Burial & Period & Pretreatment & $\begin{array}{l}\text { Laboratory } \\
\text { code }\end{array}$ & Date BP & Cal. BC/AD & $\begin{array}{l}\text { White's com- } \\
\text { ment }\end{array}$ \\
\hline BCES 12 & MPVIII & husk & OxA-5604 & $1970 \pm 60$ & $42 \mathrm{BC}-\mathrm{AD} 86$ & too young \\
\hline BCES 12 & MPVIII & sherd residue & OxA-6070 & $2980 \pm 50$ & $1298-1136$ & too old \\
\hline BCES 19 & MPVIIb & husk & OxA-5684 & $2190 \pm 70$ & $345-155$ & $\begin{array}{l}\text { younger than ex- } \\
\text { pected }\end{array}$ \\
\hline BCES 19 & MPVIIb & humics & OxA-5685 & $1695 \pm 65$ & 409-261 & \\
\hline BCES 19 & MPVIIb & sherd residue & OxA-5686 & $2590 \pm 70$ & $811-589$ & \\
\hline BCES 19 & MPVIIb & sherd residue & OxA-5687 & $2545 \pm 65$ & $774-558$ & \\
\hline BCES 40 & MPVIIa & husk & OxA-5688 & $2300 \pm 65$ & $447-251$ & $\begin{array}{l}\text { younger end of } \\
\text { expected range }\end{array}$ \\
\hline BCES 40 & MPVIIa & humics & OxA-5690 & $1850 \pm 65$ & AD 81-249 & \\
\hline BCES 40 & MPVIIa & sherd residue & OxA-5690 & $2445 \pm 80$ & $719-457$ & \\
\hline BCES 40 & MPVIIa & sherd residue & OxA-5691 & $2845 \pm 70$ & 1130-936 & \\
\hline BCES 34 & EPIVc & crushed sherd & AA-15577 & $3495 \pm 105$ & $2132-1533$ & \\
\hline BCES 56 & $\mathrm{EPVb}$ & crushed sherd & AA-15581 & $2970 \pm 60$ & $1385-1016$ & \\
\hline BCES 59 & EPVa & crushed sherd & AA-15582 & $3320 \pm 50$ & $1740-1450$ & \\
\hline BCES 34 & EPIVc & crushed sherd & AA-15577 & $3495 \pm 105$ & $2132-1533$ & \\
\hline BCES 63 & EPIVb & crushed sherd & AA- 15583 & $5805 \pm 60$ & $4800-4510$ & \\
\hline BCES 47 & EPIIIb & sherd residue & OxA-6069 & $4810 \pm 90$ & $3669-3453$ & too old \\
\hline BCES 47 & EPIIIb & husk & OxA-5605 & $2910 \pm 90$ & $1253-995$ & too young \\
\hline BCES 72 & EPII-III & crushed sherd & AA-12538 & $3470 \pm 70$ & $1950-1600$ & \\
\hline BC 46 & EPIIc & crushed sherd & AA- 15578 & $3465 \pm 100$ & $2050-1500$ & \\
\hline BC 47 & EPIIb & crushed sherd & AA-15579 & $3655 \pm 55$ & $2190-1880$ & \\
\hline BC 44 & EPI & rice phytoliths & CAMS-41264 & $3730 \pm 50$ & 2289-1978 & \\
\hline
\end{tabular}



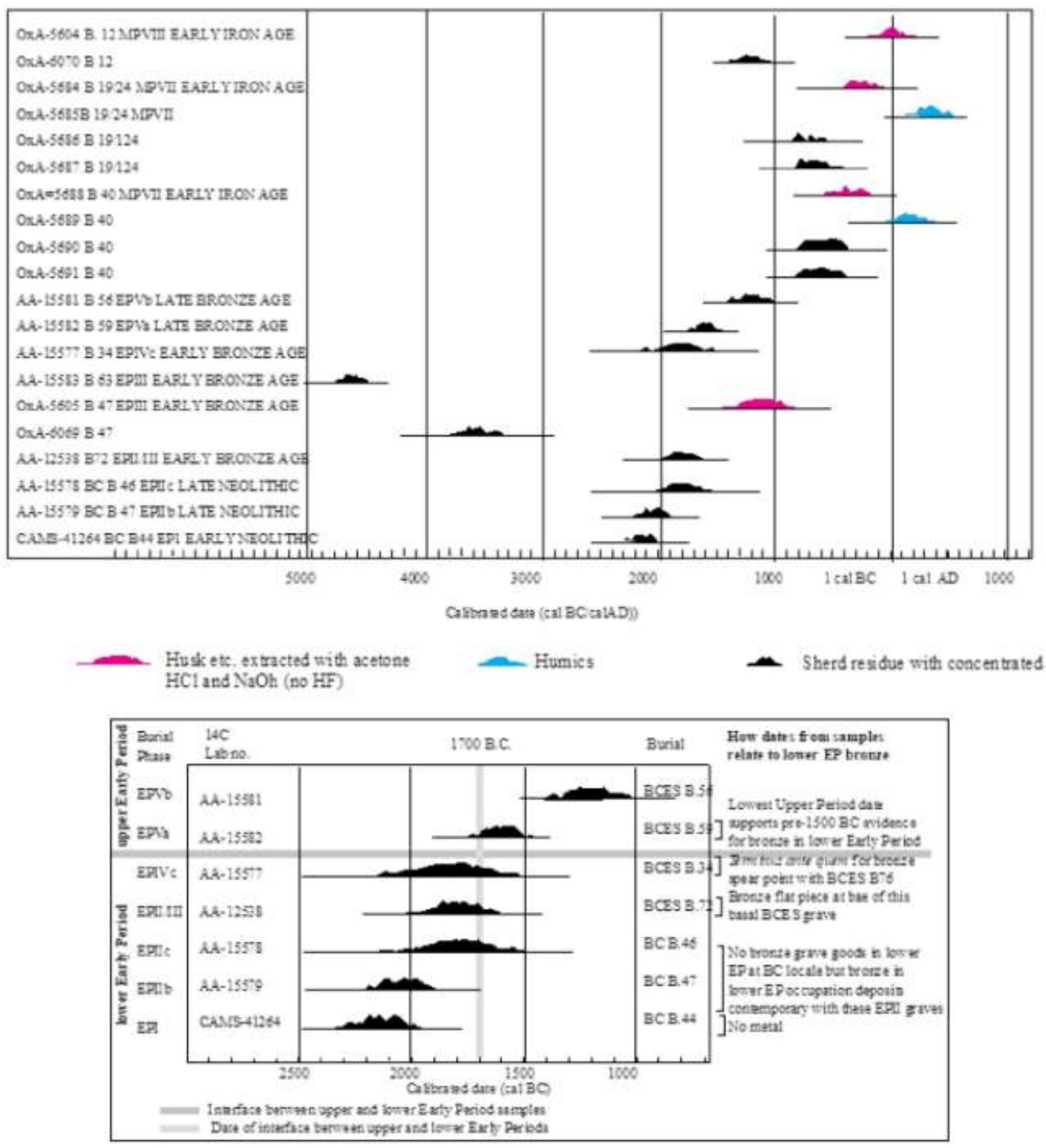

Figure 6. The AMS radiocarbon dates for ceramic temper from Ban Chiang (above, illustration by Charles Higham) and the seven chosen dates for White's chronology for this site (below, reproduced with permission from White 2008: Figure 3). 
bronze technology in Asia east of the Urals dating to about 2000 BC or shortly thereafter" (White 1997:104).

In order to provide a reliable chronology for this site, we have dated 49 human and five pig bones from the 1974-5 excavations at Ban Chiang and analyzed the results using Bayesian chronometric approaches (Figure 2; Higham et al. 2015). The resulting sequence indicates that initial Neolithic settlement took place ca. 1500 $\mathrm{BC}$, with the transition into the Bronze Age dating to ca. $1000 \mathrm{BC}$. We observe a close similarity in this with the chronological model established at Ban Non Wat (Figure 2).

White has suggested that all the new collagen bone dates are inaccurately late (White 2018:35). Is it possible, as with the Ban Non Wat sequence, to test them against determinations from charcoal, with its propensity to provide dates that might be too early because of the old wood effect? It just possibly might be, despite the trials and tribulations over understanding the location of samples and stratigraphic validity of what is being dated.

The majority of the charcoal samples from the 1974-5 excavations were accumulated from the fill of human graves, and these are clearly not from secure contexts (Higham 1984). However, we pinpoint two potential in situ samples, one of which is cited by White (2018:46) to support her long chronology. This is P2634, 1049-820 BC. It is important to stress that the provenance of these samples is by no means assured, another example of the vital importance of having the experience of the excavator. According to White (1986:176):

One or two of the layer samples (P-2455 and P-2634) may have included charcoal from possible hearths. These possible hearths were noted on the layer plans but charcoal specimens from these hearths were not specifically listed as such in the C14 Register. It is conceivable that the charcoal from the purported hearths was collected in the general layer sample.

Translated, this means that the charcoal could have been accumulated from scatters lacking a firm provenance. However, by 2018, P-2634 has categorically been transformed into an in situ hearth (White 2018:46).

Let us, for the moment assume that P-2634 is indeed from an in situ context at the junction of the lower red and the grey layer at a depth of $2.60 \mathrm{~m}$ below datum (Figure 7). The argument proceeds, that since burial 56 , with bone collagen dates of $672 \pm 86$ and $667 \pm 87 \mathrm{BC}$ lies at a depth of $3.00 \mathrm{~m}$, it must be earlier than P2634 and therefore the two bone dates in particular, and the other 52 in general, must be systematically later than reality. This argument again reflects the danger of interpreting someone else's excavation for White takes no account of the possible depth from which the grave for burial 56 was cut (Figure 7). It is highly likely to have been from a higher level than the alleged hearth and, therefore, post-date it.

There is a second sample, which probably comes from a concentration of charcoal, in the lowest cultural context of the 1975 excavation, that is known as the "lower grey stratum". The result is $2830 \pm 50 \mathrm{BP}(1126-844 \mathrm{BC})$. In Figure 8 , it is seen to lie at a depth of $2.99 \mathrm{~m}$ below datum. Note that burial 56 lies at the same location and within $60 \mathrm{~cm}$ of the charcoal. It must be later (unless the corpse was laid flat on the ground surface). Burial 56 has been ascribed to Early Period Vb, or in our sequence, the late Bronze Age. We have seen that the bone collagen date for $\mathrm{Vb}$ burial 56 is $801-753 \mathrm{BC}$. $\mathrm{EP} \mathrm{Vb}$ burial 36 is bone-dated to $768-476 \mathrm{BC}$ and EP Vb burial 27 to 787-536 BC. Figure 7 shows a schematic cross section with the depth of the 800 gr. charcoal concentration. Any burial cut from the same or a lower levels should be either of the same age, or slightly earlier than 1126-844 BC. It is stressed that the Lower Grey Stratum varies between $50 \mathrm{~cm}$ to less than one metre in depth, and the EP III early Bronze Age burials were cut down from this same layer. Burial 72 of EP II-III, Initial Bronze Age, was found about $2 \mathrm{~m}$ from the hearth at a depth of $4.05 \mathrm{~m}$ below datum. The human bone date is $2810 \pm 25$ BP (1025-900 BC) which is what one would expect for a burial cut down into the natural substrate from the Lower Grey Stratum. The other Early Bronze Age dates give similar results. 


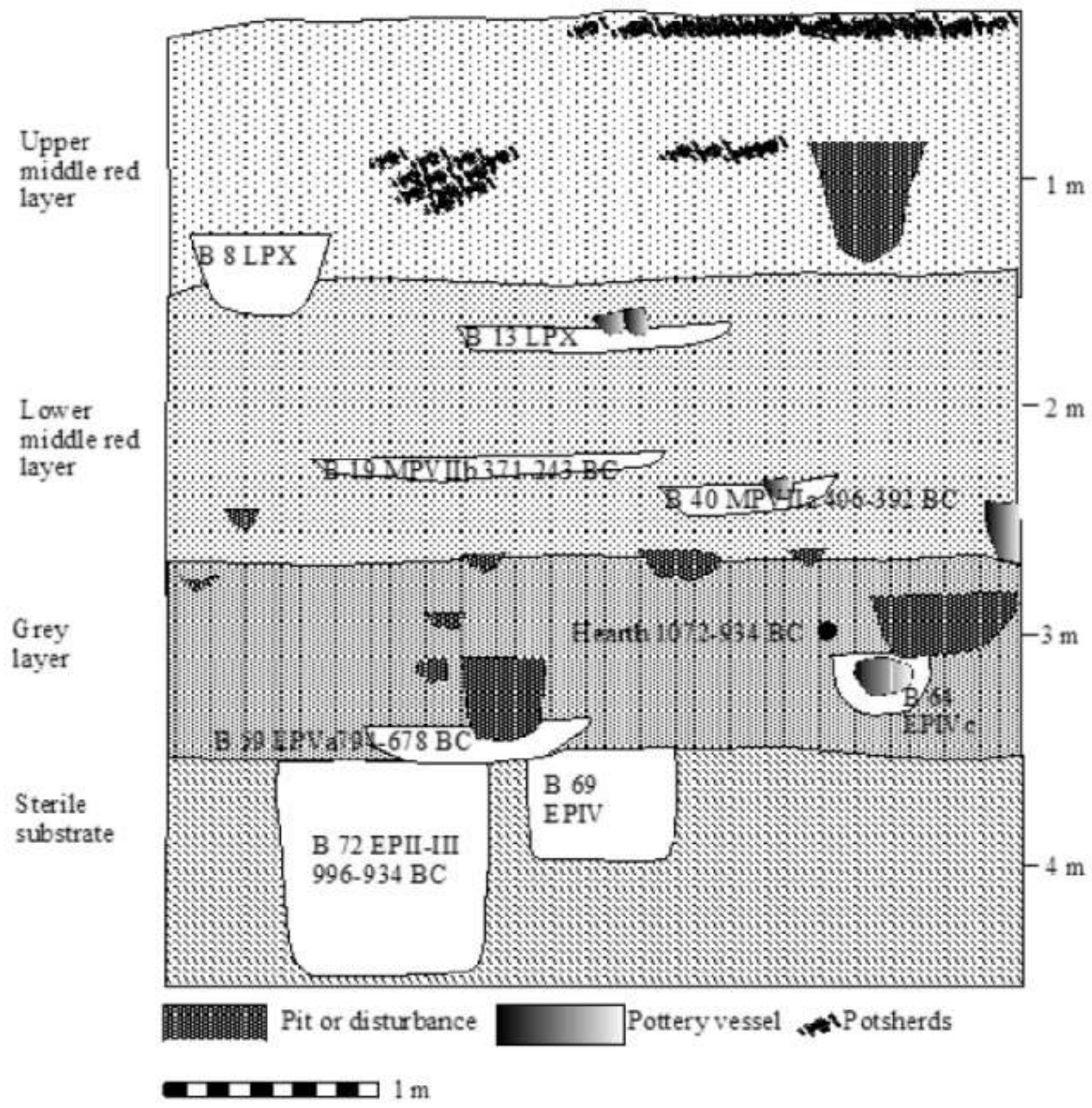

Figure 7. Cross section of square D, Ban Chiang 1975, showing the three major cultural layers, burials and relevant C14 dates. This section was generated from the plans of the excavation provided to Charles Higham by C. Gorman. Illustration by Charles Higham. 


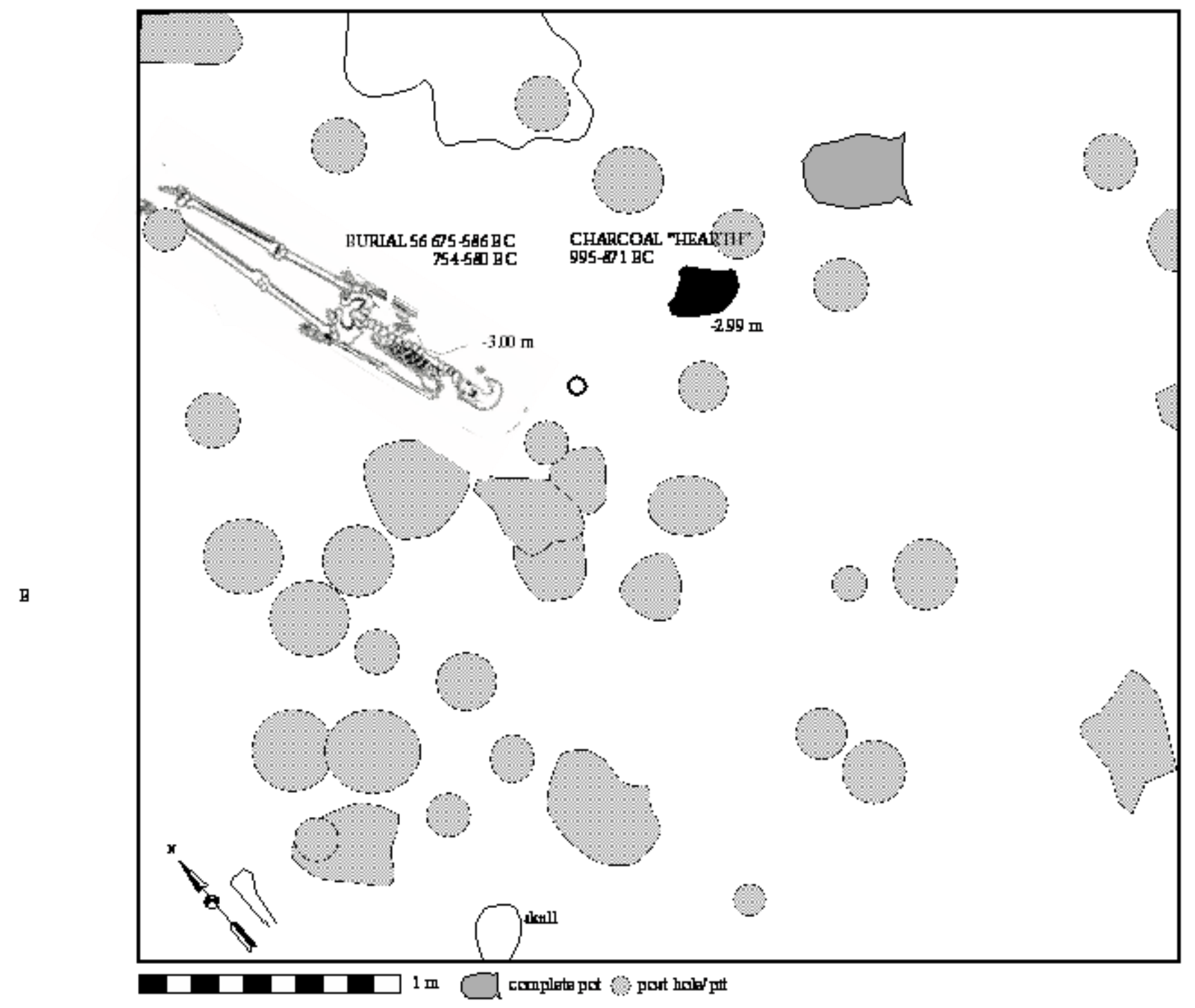

Figure 8. Plan of square D4 layer 26, Ban Chiang 1975, showing the location of a concentration of charcoal relative to burial 56, late Bronze Age. This figure was generated from the plans of the excavation provided to Charles Higham by C. Gorman. Illustration by Charles Higham. 
The date from this large in situ concentration of charcoal does not conform with White's preferred long chronology. She has gone to extreme lengths to discount its validity, by claiming that it was a "subterranean hearth" cut down and attached to flues from a higher level (White 1986:357). The site records do not support this contention. However, there is an intriguing corollary to the 21 temper/clay AMS determinations. The four determinations from pure organic temper extracted from each potsherd fit perfectly into the Bayesian sequence of bone collagen determinations (Figure 2). Thus for burial 19, the bone collagen date is $2245 \pm 27$ $\mathrm{BP}$, and the husk temper is $2190 \pm 70 \mathrm{BP}$. The bone collagen date for burial 47 is $2936 \pm 25 \mathrm{BP}$, the husk temper date is $2910 \pm 90$ BP. Freed of clay, dating of rice chaff seems a viable technique. It is unfortunate that the correct chronology for the site was present in the 1997 dating programme, but the opportunity slipped due to a prejudice in favour of early dates.

\section{CULTURAL DIVERSITY}

White (2011) is a strong proponent of cultural diversity in prehistoric Southeast Asia. Ban Chiang and Ban Na Di are a mere $20 \mathrm{~km}$ apart, and on comparing the pottery vessels from contemporary phases, she has found that:

Surprising differences in nearby sites first became evident when the pottery sequence of the prehistoric site of Ban Chiang was compared in detail with that of Ban Na Di located only 20 kilometers away (White 1986:234). Based on radiocarbon dates, the main cemetery deposit at Ban Na Di primarily overlaps the Ban Chiang Middle Period cemetery dating from the early to the middle of the first millennium BC. The usual archeological assumption that two such close sites would share the same cultural tradition (Higham and Kijngam 1984) proved hard to specify ceramically, contemporaneous deposits at the two sites had so few stylistically similar ceramics that it was difficult to crossdate the two sites. (White 1995:105).

Again:
Excavations in Thailand are producing unexpected site-to-site variability in material culture that are suggestive of small localized cultures (White 1986:337). While further excavation is required to confirm this observation and develop tighter spatial and chronological control over the data, there is some basis to suggest that there was a marked enduring localism evident in material culture, ritual, and social practices between 2000 and 200 BC." (White 1995:105).

And:

Pottery decorative techniques and sets of related forms recur among contemporary burials and can last hundreds of years. It has been sites like these that have impressed me with the formal ceramic diversity represented in the Ban Chiang pottery, one is hard pressed to find repeated types and little sense of continuous formal evolution. (White 1994:5).

It is therefore, surprising that under the heading "Red Flag Bone Dates", White (2018:36) has entered into a detailed argument to undermine the shell, charcoal and rice grain dates from Ban Non Wat and bone dates from Ban Chiang that merits close examination. It turns on a comparison between a single pottery vessel from Neolithic 1 burial 28 at Ban Non Wat and two from Ban Chiang ascribed to her Lower Period IIC (late Neolithic) burials 43 and 46 (Figure 9 shows her illustration of these). White argues that they "share distinctive commonalities in manufacture and use, and therefore, they should be contemporary". But, her argument proceeds, the radiocarbon shell date for burial 28 at Ban Non Wat (3170 \pm 27 BP, 1501-1406 $\mathrm{BC})$ is earlier than the bone dates for burial 43 $(2984 \pm 26$; $1285-1119$ BC) and burial 46 (2958 \pm 29 BP; 1261-1056 BC). Therefore the radiocarbon dates are unreliable because the similarities in the three pots, she writes, "would need to have existed very close in archaeological time".

There are more differences than similarities between these pots. The upper panel of decoration from Ban Non Wat is incised and painted, whereas the Ban Chiang pots have a much wider band that is incised and impressed. The resulting patterns differ. White's illustration 
gives the impression that the three pots are similar in size (reproduced as Figure 9). However the Ban Non Wat pot is in fact, double in size compared to the two Ban Chiang examples. Her illustration is corrected in Figure 10. Surely, in comparing pottery vessels from two different sites, one should include all forms. Every pot from Ban Non Wat has been published, but we do not have corresponding information from Ban Chiang, and what is available keeps changing. Thus the pot from burial 46 as illustrated in White (2008: Figure 2) has no hint of the painted decoration that has surfaced on the same pot in White (2018:37 (Figure 2.8)), together with some fresh fractures and a different size (see Figure 10). Figure 11 illustrates Early Neolithic pottery vessels from Ban Non Wat and Ban Chiang. These confirm White's contention that pottery styles can be totally different within $25 \mathrm{~km}$ of each other --- even within the same time period. White then proceeded to cite the dating of the Neolithic ceramic assemblage from An Son in southern Vietnam in support of her long chronology. An Son is 1,000 km from Ban Chiang, and could well represent a different, perhaps coastal, expansionary route for early Neolithic farmers. Even if the two sites represent the same migratory group, this is an argument that is the equivalent of expecting LBK sites in Eastern Hungary to have the same date as those in the Paris Basin.

\section{WHAT CONSTITUTES EVIDENCE FOR THE START OF THE BRONZE AGE?}

There is no argument that a person interred in association with a copper-base artifact represents a Bronze Age context. The same is true for an in-situ casting facility, such as a hearth for raising copper to melting point ringed by fragments of casting spillage, crucibles and moulds. We are not prepared to accept as evidence, scraps of bronze, or fragments of crucible, from non-mortuary contexts. This scepticism results from the experience of excavating several sites with a sequence spanning the Neolithic and Bronze Ages, including Ban Chiang. These sites are honeycombed with disturbances and the results of bioturbation. At certain contexts of Ban Non Wat, fragments of iron found their way into layers otherwise Neolithic, and as many as 50 copper-base fragments of metal were recovered from Neolithic layers, admittedly in an excavated area 15 times the size of 1975 Ban Chiang.

White has argued that the sophistication of a socketed bronze spear from Ban Chiang EP IIIa (early Bronze Age), which we have dated to 1056-919 BC means that there must be an earlier developmental phase at this site. The lead isotope signature aligns this artefact with the copper source at Vilabouly in Laos (Pryce et al. 2014), and it is likely that it is an import to Ban Chiang. There are very few copper-base fragments in non mortuary contexts at Ban Chiang that predate the first burial with a bronze (White and Hamilton 2019:220). We encourage caution in interpreting this situation.

White and Hamilton (2009:363) have searched Southeast Asia for evidence supporting their long chronology that places the initial Bronze Age at ca. 2000-1800 BC. They cite Non Nok Tha thus:

There is evidence that the oldest metal there, including a remarkable, thin-walled, deepsocketed tin-bronze implement (known by the nickname 'WOST', for 'World's Oldest Socketed Tool'; Fig. 2c), could date to the late third millennium $\mathrm{BC}$.

We have dated 15 human bone collagen samples from this site and find that the transition from the late Neolithic into the early Bronze Age is about 1000 BC (Figure 12) hence invalidating this argument. The second alleged parallel is a "bronze bar" from the Central Thai site of Ban Mai Chaimongkol that has been

cross-dated to some time during the early second millennium $\mathrm{BC}$, based on its position in the Ban Mai Chaimongkol ceramic sequence relative to dated ceramic sequences from other sites in central Thailand.

We would like to know which dated ceramic sequences are in question for dating a bar that is identical to the 10th century BC chisels from Ban Non Wat. 


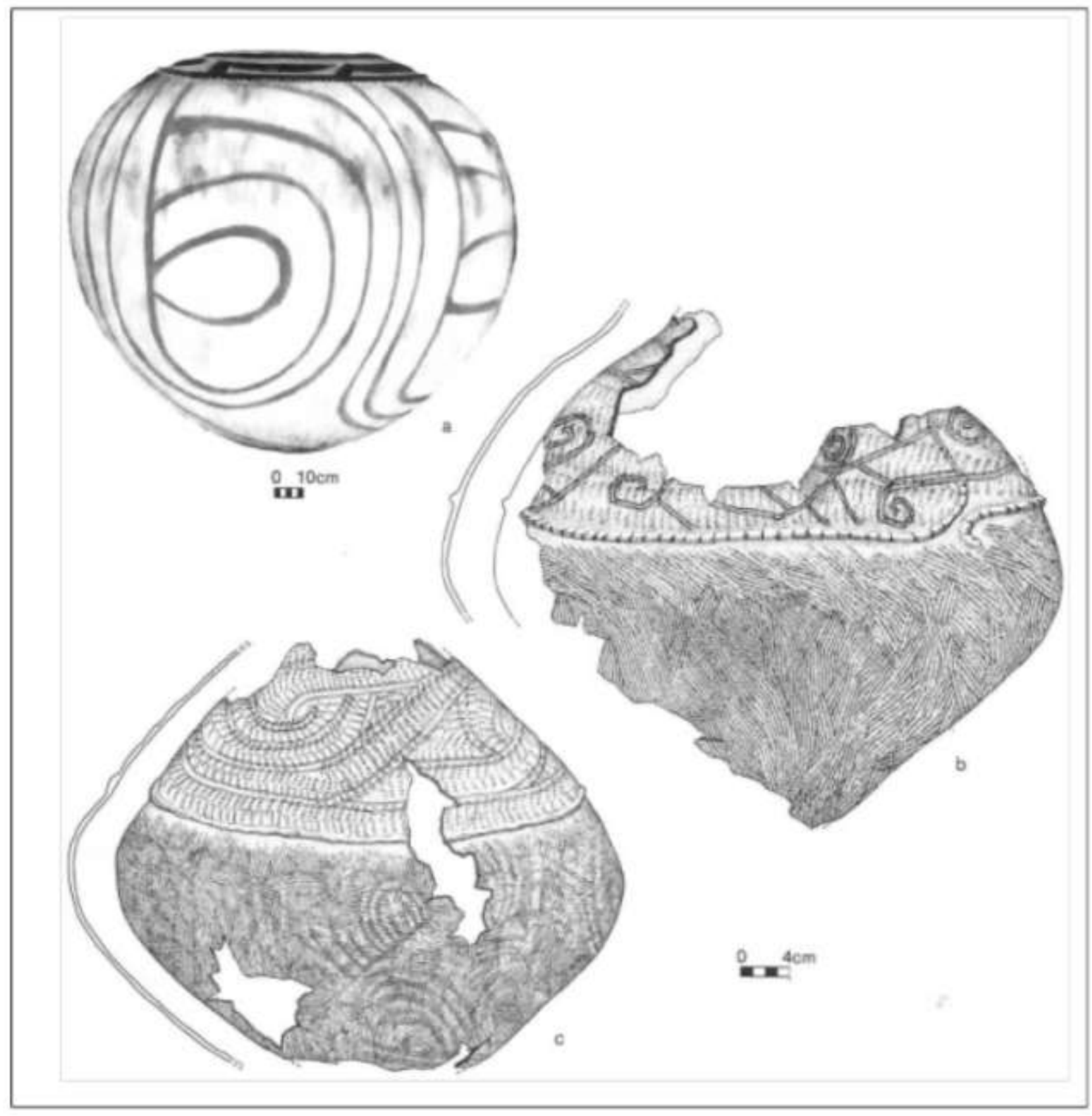

Figure 9. White (2018:Figure 2). Reproduced, including (a) originally published by Higham (2014:114). Her caption, "Possible comparanda from early phases at Ban Chiang and Ban Non Wat. (a) Example of a BNW Neolithic 1 burial jar that contained an adult, Burial 28 cat. 1039. (b) the i\&i burial jar for BC" Burial 43 Pot A 1374. (c) Example of a lower Early Period Phase IIc i\&i burial jar. Reproduced by permission of the University Museum, Philadephia. 


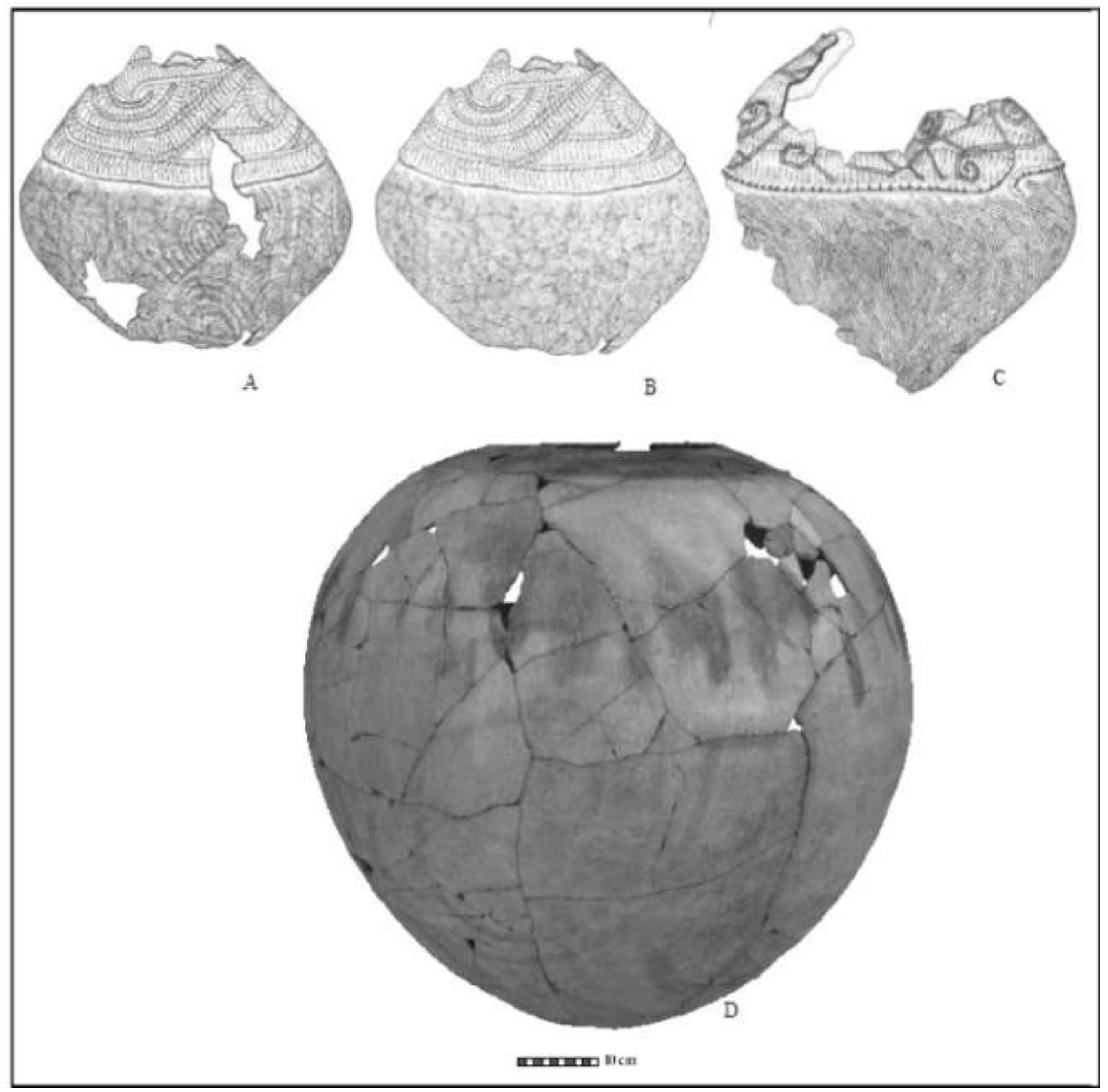

Figure 10. White's "comparanda" at the correct scale. Notice how fractures and painted designs have mysteriously appeared on pot $A$ between 2008 and 2019. A. Ban Chiang burial 46 pot A, B. the same pot as published in White (2008:Figure 2), C. Ban Chiang burial 43 C14 2984 \pm 26 BP, D. Ban Non Wat burial 28 cat. 1039 C14 $3170 \pm 27$ BP. A-C reproduced by permission of the University Museum, Philadephia. D, photograph by Charles Higham. 


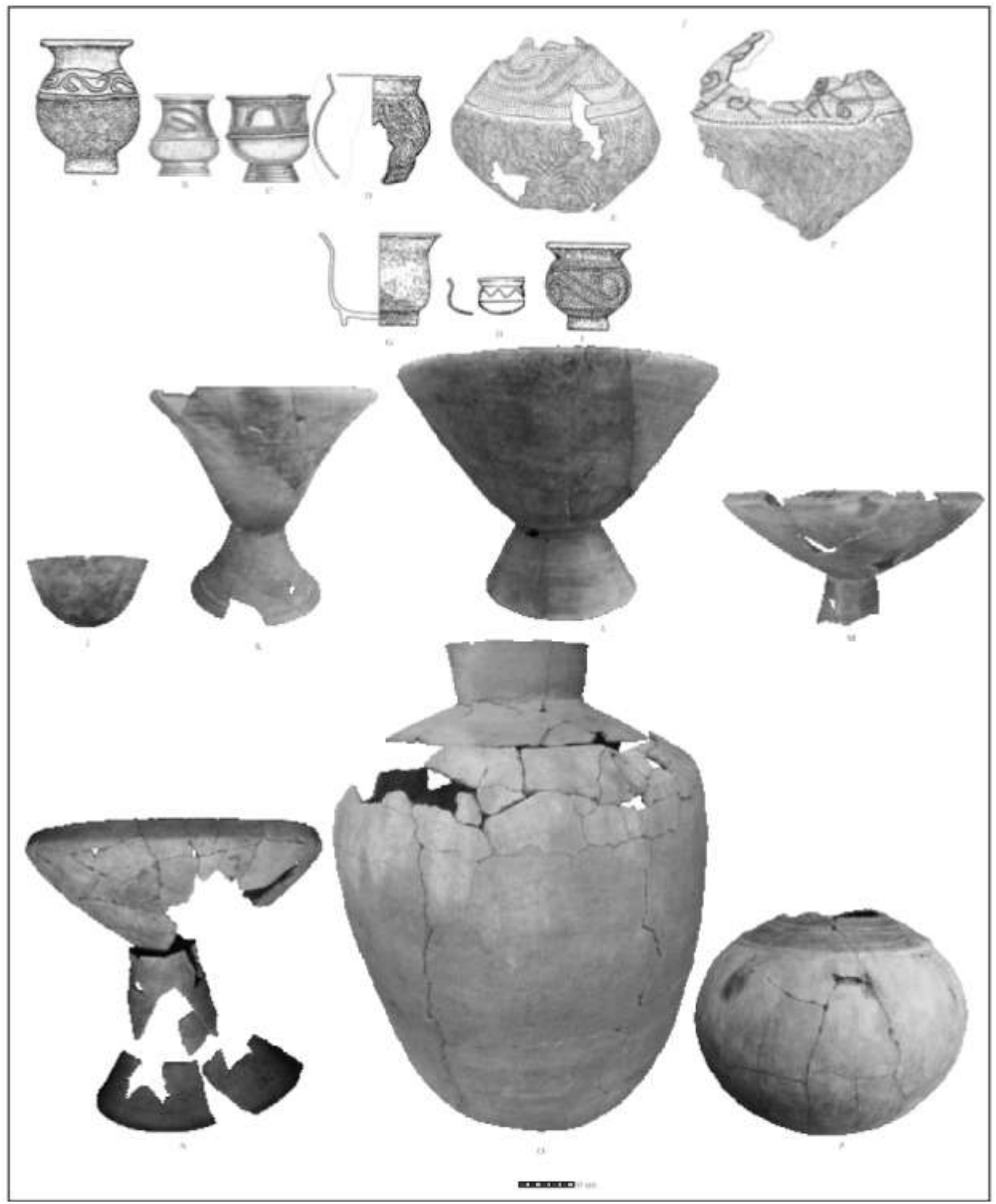

Figure 11. Neolithic ceramic vessel comparanda from Ban Chiang and Ban Non Wat. A. Ban Chiang Early Period; B. BC lower EPI; C. BC burial 44 EPI $(3242 \pm 26$ BP); D. BCES burial 57 EPIIc, E. BCES burial 46 EPIIc; F. BC burial 43 EPIIc $(2984 \pm 26$ BP $) ; G$ H I BNW burial 86 (3100 28 BP); J. BNW burial 298; K. BNW burial 250; L. BNW burial 292; M. BNW burial 103. A-D, reproduced by permission Dr. W. Wiriyaromp. E-I, reproduced by permission of the University Museum, Philadephia. G-I, illustrations by Charles Higham. $J-P$, photographs by Charles Higham. 


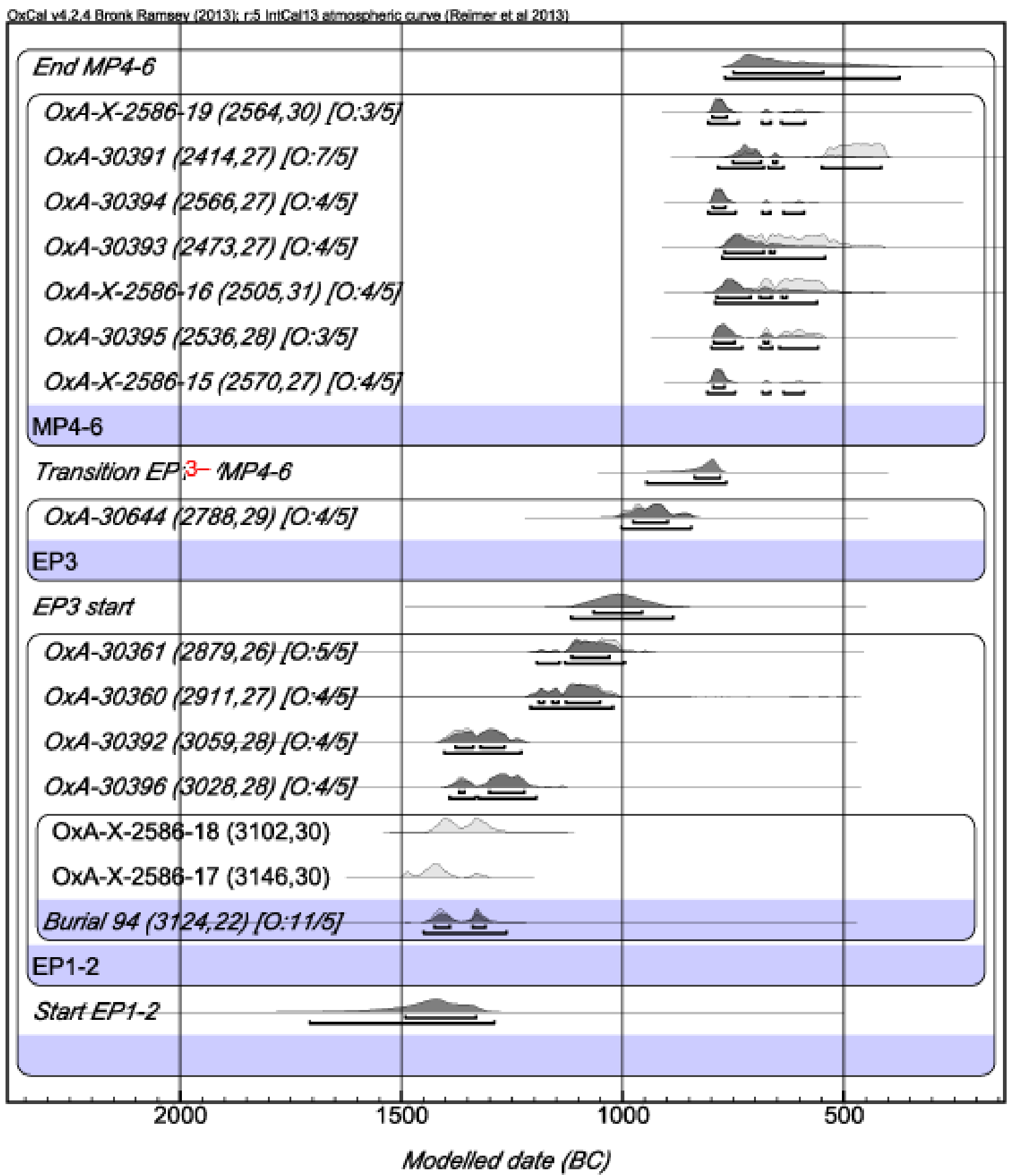

Figure 12. Bayesian plot for the radiocarbon dates from human bone collagen, Non Nok Tha. EP1-2 is Neolithic, EP3 is the initial Bronze Age (reproduced under a Creative Commons Attribution Licence from Higham et al. 2014). 
Relative dating via association or parallels with ceramic sequences from other sites is dangerous and lacks the rigour of direct scientific dating of burials and other secure contexts. White and Hamilton also cite evidence for early 2nd millennium $\mathrm{BC}$ bronze in Vietnam, a region lacking secure and reliable dating. In other words, there is no evidence in Southeast Asia to support their long chronology.

\section{CONCLUSIONS}

We are confronted with two alternative chronologies. Our short chronology is derived from over 200 new AMS radiocarbon determinations from key sites on the basis of charcoal, rice grains, freshwater shells and bone collagen. We have dated the initial Neolithic at Man Bac in northern Vietnam, a major site in identifying the arrival of early farming communities, around 1900-1500 BC (Vlok et al. 2019). Khok Phanom Di, the classic Neolithic site of coastal Central Thailand, was first settled in about 2000 BC. Yao and Darre (2019) have dated the late Neolithic at Hebosuo and Shangxihe in Yunnan between 1300-1000 BC. There are four phases at the Neolithic settlement and cemetery of Nong Ratchawat in Suphanburi, Central Thailand (Doungsakun nd). These are divided into early and late Neolithic phases. Initial settlement is dated to about $2000 \mathrm{BC}$, and the end of the late Neolithic to $1256-1146$ BC. Over 500 $\mathrm{m}^{2}$ have been excavated there including habitation layers and separate burial ground with 111 graves. No bronze was encountered despite the fact that the site is only $100 \mathrm{~km}$ west of the Khao Wong Prachan copper deposits. The Neolithic occupation of Non Pa Wai and Non Mak La dates to a similar time span (Weiss and Pigott 2017), with the transition to the first evidence for copper exploitation following in the late 2nd millennium BC. The virtually identical date for early bronze in north central Myanmar suggests that there was a geographically wide and uniform front to this uptake (Pryce et al. 2018).

White (2018), in contrast, places the initial Bronze Age at Ban Chiang contemporary with or even earlier than the arrival elsewhere in Southeast Asia of the first farmers. This distorts a clear emerging pattern. White and Hamilton (2009:370) have written that:

The absence of evidence for metalworking in contemporaneous sites in some parts of Thailand (for example, Khok Phanom Di and Khok Charoen) suggests some villages were part of a circuit of production, and some were not.

Khok Phanom Di was occupied between 2000 $1500 \mathrm{BC}$. In four different excavations there, no bronze has ever been found (Higham and Thosarat 2004). Located on the estuary of the Bang Pakong River in Central Thailand, it was a major emporium of trade, bringing in exotic shell for ornaments, stone for adzes, ochre for mortuary rituals, and exporting shell beads to Neolithic sites in the vicinity of the future copper mines of the Khao Wong Prachan Valley $110 \mathrm{~km}$ to the north. Khok Phanom Di and Khok Charoen were Neolithic sites occupied centuries before the first bronzes reached Southeast Asia.

There are thus two alternative models for dating the start of the Bronze Age in Mainland Southeast Asia. The first, based on seven handpicked, highly suspect and internally contradictory radiocarbon determinations based on unreliable material (crushed potsherds), would have a rapid movement of Seima Turbino specialists from the Altai mountains of Siberia to reach Ban Chiang in Thailand about 2000-1800 BC. On arrival, they cast a socketed spear that bears no resemblance to those in their distant homeland, and seemingly made from copper mined and smelted hundreds of kilometres to the southeast where no evidence for metallurgical activity this early has been found. This, according to White's model, was then followed by a still-stand for nearly a millennium before this most significant technological advance spread to any other site in Southeast Asia.

The second, based on several hundred radiocarbon dates, traces the spread of early rice and millet farmers south from the Neolithic heartlands in the Yangtze and Yellow River valleys via multiple routes, dating from the late 3rd to mid 2nd millennia BC, to be followed from ca. $1100 \mathrm{BC}$ onwards by exchange in copper-base artifacts and probably, the ingress of experi- 
enced bronze miners and founders, again from the north.

Accepting the former long chronology would have a somnolent Bronze Age with no evidence for social change at Ban Chiang. The short chronology has identified a rapid rise of elite aggrandizers in the strategic upper Mun Valley at Ban Non Wat and Ban Prasat (Higham 2011). It sees Ban Chiang being occupied by rice farmers in the 16th century BC, followed by the transition into the Bronze Age in about 1000 BC. Situated in a remote corner of Northeast Thailand, far from natural exchange routes, the Bronze Age dead we know of at Ban Chiang from excavated contexts were poorly endowed with mortuary offerings.

We conclude that a solid chronological foundation has now been laid for the region. This allows researchers to pursue important issues stemming from the introduction of metals in Southeast Asia, and we hope that final excavation report on the 1974-5 excavations from Bang Chiang will finally put further controversy over chronology to rest.

\section{ACKNOWLEDGMENTS}

We thank the Marsden Fund of the Royal Society of New Zealand for funding the research programme "A passage of time: dating the prehistory of southern China and Southeast Asia". We are grateful to the authoritis of the Penn Museum for allowing us to reproduce images. Three reviewers are thanked for their constructive comments.

\section{REFERENCES}

Armit, I. 2015. Review of excavations at Call Donnain. Antiquity 89:755.

Bayliss, A., C. Bronk Ramsey, J. van der Plicht and A. Whittle. 2007. Bradshaw and Bayes: towards a timetable for the Neolithic. Cambridge Archaeological Journal 17(1) (Supplement): 1-28.

Berstan, R., A.W. Stott, S. Minnit, C. Bronk Ramsey, R.E.M. Hedges and R.P. Evershed. 2008. Direct dating of pottery from its organic residues: new precision using compoundspecific carbon isotopes. Antiquity 82:702713.
Bonsall, C., G. Cook, J. Manson and D. Anderson. 2002. Direct dating of Neolithic pottery: Progress and prospects. Documenta Praehistorica 29:47-59.

Castillo, C.C., C.F.W. Higham, K. Miller, N. Chang, K. Douka, T.F.G. Higham and D.Q. Fuller. 2018. Social responses to climate change in Iron Age Northeast Thailand: New archaeobotanical evidence. Antiquity 92:1274-1291.

Dal Martello, R., R. Min, C. Stevens, C.F.W. Higham, T.F.G. Higham, L. Qin and D.Q. Fuller. 2018. Early agriculture at the crossroads of China and Southeast Asia: Archaeobotanical evidence and radiocarbon dates from Baiyangcun, Yunnan. Journal of Archaeological Science: Reports 20:711721.

Doungsakul, S. nd. Recent research on Ban Kao culture, western Thailand. Unpublished report.

Glusker, D. and J.C. White. 1997. Comment. Archaeometry 39:259-260.

Gorman, C.F. and P. Charoenwongsa. 1976. Ban Chiang: a mosaic of impressions from the first two years. Expedition 8:14-26.

Higham, C.F.W. 1984. The Ban Chiang culture in wider perspective. Proceedings of the British Academy LXIX:229-261.

Higham, C.F.W. 2011. The Bronze Age of Southeast Asia: New insight on social change from Ban Non Wat. Cambridge Archaeological Journal 21(3):365-389.

Higham, C.F.W. 2014. Early Mainland Southeast Asia: From first humans to Angkor. Bangkok: River Books.

Higham, C.F.W., K. Douka and T.F.G. Higham. 2015. A new chronology for the Bronze Age of Northeastern Thailand and its implications for Southeast Asian prehistory. Plos One. http://journals.plos.org/plosone/article?id=10 .1371/journal.pone.0137542

Higham, C.F.W. and T.F.G. Higham. 2009. A new chronological framework for prehistoric Southeast Asia, based on a Bayesian model from Ban Non Wat. Antiquity 82:1-20.

Higham C.F.W., T.F.G. Higham and K. Douka. 2014. The chronology and status of Non Nok 
Tha, Northeast Thailand. Journal of IndoPacific Archaeology 34:61-75.

Higham, C. F. W. and A. Kijngam (eds.). 1984. Prehistoric Excavations in Northeast Thailand: Excavations at Ban Na Di, Ban Chiang Hian, Ban Muang Phruk, Ban Sangui, Non Noi and Ban Kho Noi. Oxford: British Archaeological Reports, International Series 231(i-iii).

Higham, C.F.W. and A. Kijngam (eds.). 2009. The Origins of the Civilization of Angkor. Volume III. The Excavation Ban Non Wat, Introduction. Bangkok: The Fine Arts Department of Thailand.

Higham, C.F.W. and A. Kijngam (eds.). 2012. The Origins of the Civilization of Angkor. Volume V. The Excavation Ban Non Wat: the Bronze Age. Bangkok: The Fine Arts Department of Thailand.

Higham C.F.W., Y.V. Kuzmin and G.S. Burr. 2010. The AMS 14C dating of Iron Age rice chaff ceramic temper from Ban Non Wat, Thailand: First results and its interpretation. Nuclear Instruments and Methods in Physics Research B 268:1022-1225.

Higham, C.F.W. and R. Thosarat. 2004. The Excavation of Khok Phanom Di: Volume VII. Summary and Conclusions. London: The Society of Antiquaries of London.

Hillman, A., M.B. Abbot, J. Yu, D.J. Bain and T. Chiou-Peng. 2015. Environmental Legacy of Copper Metallurgy and Mongol Silver Smelting Recorded in Yunnan Lake Sediments. Environmental Science and Technology 49:3349-3357.

Pryce T.O. 2009. Copper Production and Technological Reproduction in the Khao Wong Prachan Valley of Central Thailand. Unpublished Ph.D. thesis, UCL Institute of Archaeology, University College London, London. Available at http://oxford.academia.edu/Oliver Pryce.

Pryce, T O., M. Brauns, N. Chang, E. Pernicka, M. Pollard, C. Ramsey, T. Rehren, V. Souksavatdy and T. Sayavongkhamdy. 2011. Isotopic and technological variation in prehistoric primary Southeast Asian copper production. Journal of Archaeological Science 38:3309-3322.
Pryce T.O., A.A. Kyaw, M.M. Kyaw, T.T. Win, T.T. Win, K.H. Win, M.M. Mon, M. M. Aye, S.H. Htay, A.A. Mar, B. Bellina, R.A. Bentley, L. Champion, C. Colonna, A.J. Cook, A. Favereau, D.Q. Fuller, C. Georjon, C.F.W. Higham, K.M.M. Htwe, Y. Iizuka, J. Innanchai, C. Le Meur, X. Peixoto, P. Petchey, R. Pinhasi, B. Pradier, F. Valentin, A. Willis and A. Zazzo. 2018. A first absolute chronology for Late Neolithic to Early Bronze Age Myanmar: New AMS C-14 dates from Nyaung'gan and Oakaie. Antiquity 92:690-708.

Pryce, T.O., M. Martinón-Torres, V.C. Pigott and T. Rehren. 2010. Prehistoric copper production and technological reproduction in the Khao Wong Prachan Valley of Central Thailand. Archaeological and Anthropological Sciences 2:237-364.

Pryce, T.O., S. Baron, B.H.M. Bellina, P. Bellwood, N. Chang, P. Chattopadhyay, E. Dizon, I.C. Glover, E. Hamilton C.F.W. Higham, A.A. Kyawi, V. Laychour, S .Natapintu, V. Nguyen, J-P Pautreau, E. Pernicka, V.C. Pigott, M. Pollard, C. Pottier, A. Reinecke, T. Sayavongkhamdy, V. Souksavatdy and J.C. White 2014. More questions than answers: The Southeast Asian lead isotope project 2009-2012. Journal of Archaeological Science 42: 273-294.

Vlok M., H.R. Buckley, M. Oxenham, K. Domett, T.T. Minh, N.T.M. Huong, H. Matsumura, H.H. Trinh, C.F.W. Higham, T.F.G. Higham and N.T. Huu. In press. Two probable cases of infection with treponema pallidum during the Neolithic period in northern Vietnam ( 4000-3500BP). Science Advances.

Weiss, A. and V.C. Pigott. 2017. Here we go again. A new series of AMS dates from the Khao Wong Prachan Valley, Central Thailand. Paper presented at the Society for American Archaeology Meeting, Vancouver.

White, J.C. 1986. A Revision of the Chronology of Ban Chiang and its Implications for the Prehistory of Northeast Thailand. Unpublished Ph.D. dissertation. Philadelphia: University of Pennsylvania. 
White, J.C. 1994. A critique of "Chronometric Hygiene and the Bronze Age of Southeast Asia", a paper presented by Charles Higham at the Indo-Pacific Prehistory Association, January 1994, in Chiang Mai, Thailand.

White, J.C. 1995. Incorporating heterarchy into theory on socio-political development: The case from Southeast Asia. In R. Ehrenreich, C. Crumley and J. Levy (eds.), Heterarchy and the Analysis of Complex Societies, pp. 101-123. Washington D.C.: American Anthropological Association.

White, J.C. 1997. A brief note on new dates for the Ban Chiang cultural tradition. Bulletin of the Indo-Pacific Prehistory Association 16:103-106.

White, J.C. 2008. Dating early bronze at Ban Chiang, Thailand. In J.-P. Pautreau, A.-S. Coupey, V. Zeitoun and E. Rambault (eds.), From Homo erectus to the Living Traditions, pp. 91-110. Bougon: European Association of Southeast Asian Archaeologists.
White, J.C. 2011. Cultural diversity in mainland Southeast Asia: a view from prehistory. In N.J. Enfield (ed.), Dynamics of Human Diversity: The Case of Mainland Southeast Asia, pp. 9-46. Pacific Linguistics 627. Canberra: The Australian National University.

White, J.C. 2015. Comment on Higham et al. (2015) re New Chronology for Northeast Thailand. Plos One 10(9). https://doi.org/10.1371/journal.pone.013754.

White, J.C. 2018. Ban Chiang, Ban Tong, Ban Phak Top and Don Klang: Summary of excavations and sequences. In J.C. White and E. Hamilton (eds.), Ban Chiang, Northeast Thailand. Volume 2A: Background to the Study of the Metal Remains, pp. 21-46. Philadelphia: University of Pennsylvania Press.

White J.C. and E. Hamilton. 2009. The transmission of early Bronze Age technology to Thailand: new perspectives. Journal of World Prehistory 22:357-397.

Yao, A. and V. Darre. 2019. Bridging the time gap in the Bronze Age of Southeast Asia and Southwest China. Plos One, in press. 